NATURE INDEX | COLLABORATIONS

at Dana-Farber/Boston Children's

Cancer and Blood Disorders Center.

Hong and colleagues grew a cell line

from a rare cancer sample to learn how

they might exploit any weaknesses.

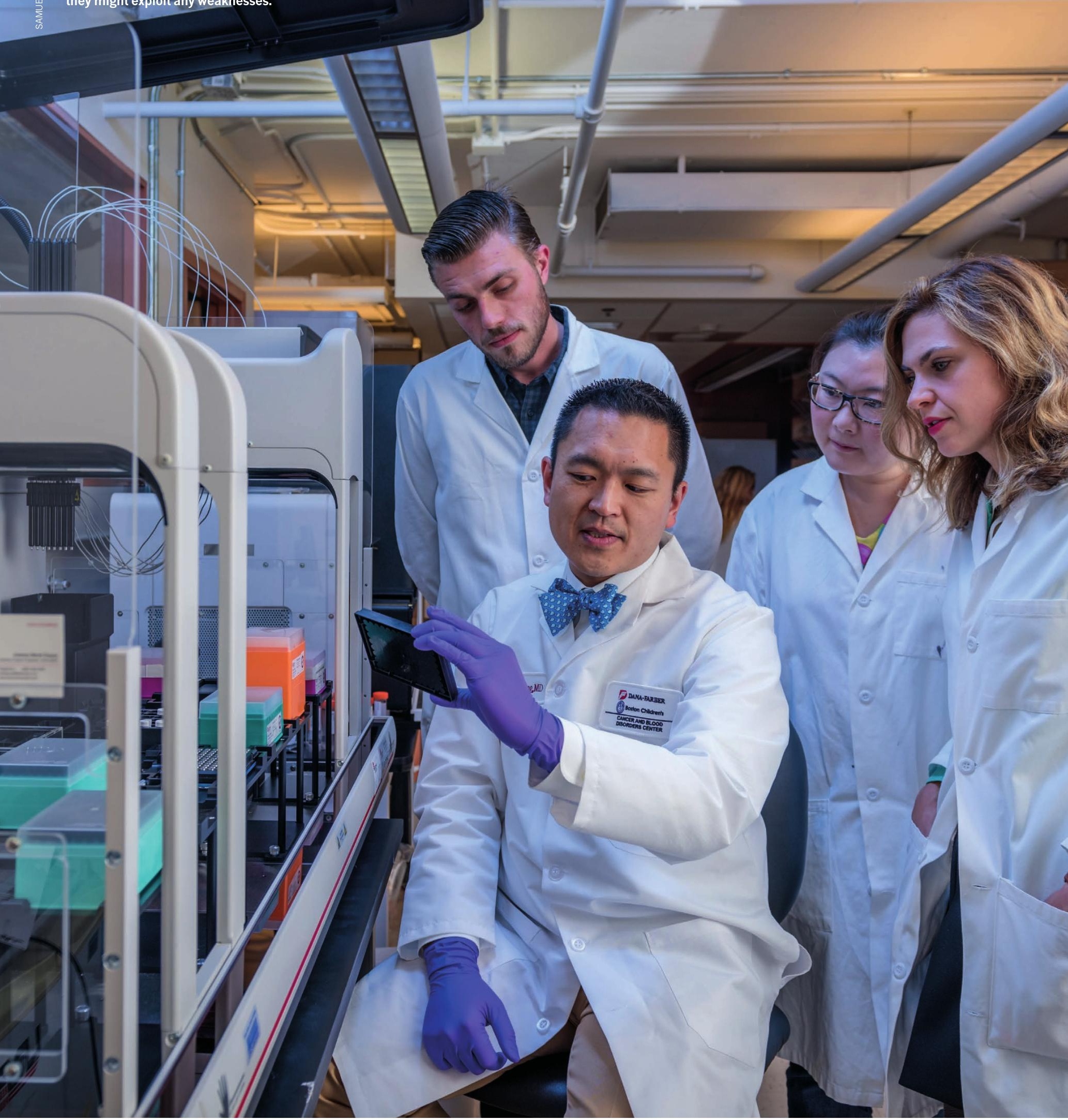




\title{
APPLYING LOCAL KNOWLEDGE
}

\author{
Proximity is just one factor driving the high \\ number of collaborations between top performing \\ institutions in the same city.
}

BY NEIL SAVAGE

A $s$ a researcher working on treatments for children with cancer, Andrew Hong has been frustrated by the lack of therapy. Cancers that show up in only a tiny number of children haven't been extensively studied, precisely because their occurrence is so rare that there are few opportunities for research.

"It was really hard when we had to look in parents' eyes and tell them we didn't have anything to offer their child," says Hong, a doctor at Boston Children's Hospital, instructor at Harvard Medical School and Dana-Farber Cancer Institute, and researcher at the Broad Institute, a joint venture of Harvard University and the Massachusetts Institute of Technology (MIT).

But the dearth of treatments for children with rare cancers may start to change. Hong and researchers from several institutions in the Boston area have teamed up to show they can grow a cell line from a rare cancer sample and use several new technologies to learn about its potential weaknesses.

Hong's group is just one example of a phenomenon apparent in the tally of papers in Nature Index; a lot of high-quality research comes from collaborations among people at institutions in the same city. Collaborators are often just a subway ride or a walk apart. Of the 100 strongest partnerships between two institutions around the world, nearly half are between research organizations in the same city, some are only a few kilometres apart.

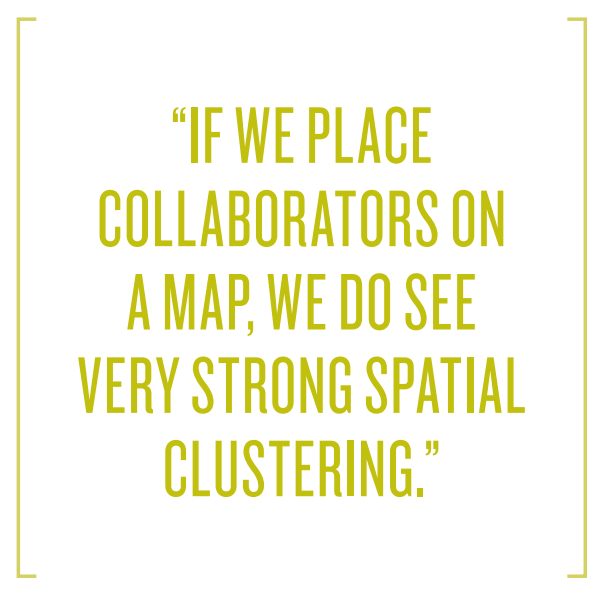

"If we place collaborators on a world map we do see very strong spatial clustering in a very limited number of hotspots," says Riccardo Crescenzi, professor of economic geography at the London School of Economics and Political Science. He has studied patents filed in the European Patent Office by co-inventors from different institutions, at least one of whom was in the UK, as well as research cooperation between academia and industry, and found that a strong correlation between proximity and co-invention.

Geographical proximity is not the driving factor, Crescenzi argues. Rather people are often located close to each other physically because they move in the same social and institutional circles.

Nature Index shows, for instance, that the world's strongest collaboration between two institutions is between Harvard and MIT, which are separated by only three kilometres along the banks of the Charles River in Cambridge, Massachusetts. Their strong collaboration is driven partly by a joint venture called the Broad Institute. Harvard also collaborates frequently with Boston University, just across the river, and with Tufts in nearby Medford, accessible along the same subway line as MIT.

The Boston hub isn't unique. Peking University in Beijing is another prolific collaborator. Its researchers work with colleagues at the Institute of Chemistry and the Institute of Physics, both branches of the Chinese Academy of Science located in Beijing, as well as Beijing-based Tsinghua University.

Paris also has a high number of research schools that work together (see S14), as do the Berkeley and San Francisco branches of the University of California, neighbors in the Bay Area. 


\section{IN CLOSE RANGE}

Of the 100 strongest partnerships between two institutions around the world, nearly half are between pairs of research organizations in the same city, or metro area, including these eight pairs, many only a few kilometres apart. The collaborative effort between two institutions is known as a bilateral collaboration score (CS). This is the sum of the fractional count from papers with authors from both institutions.

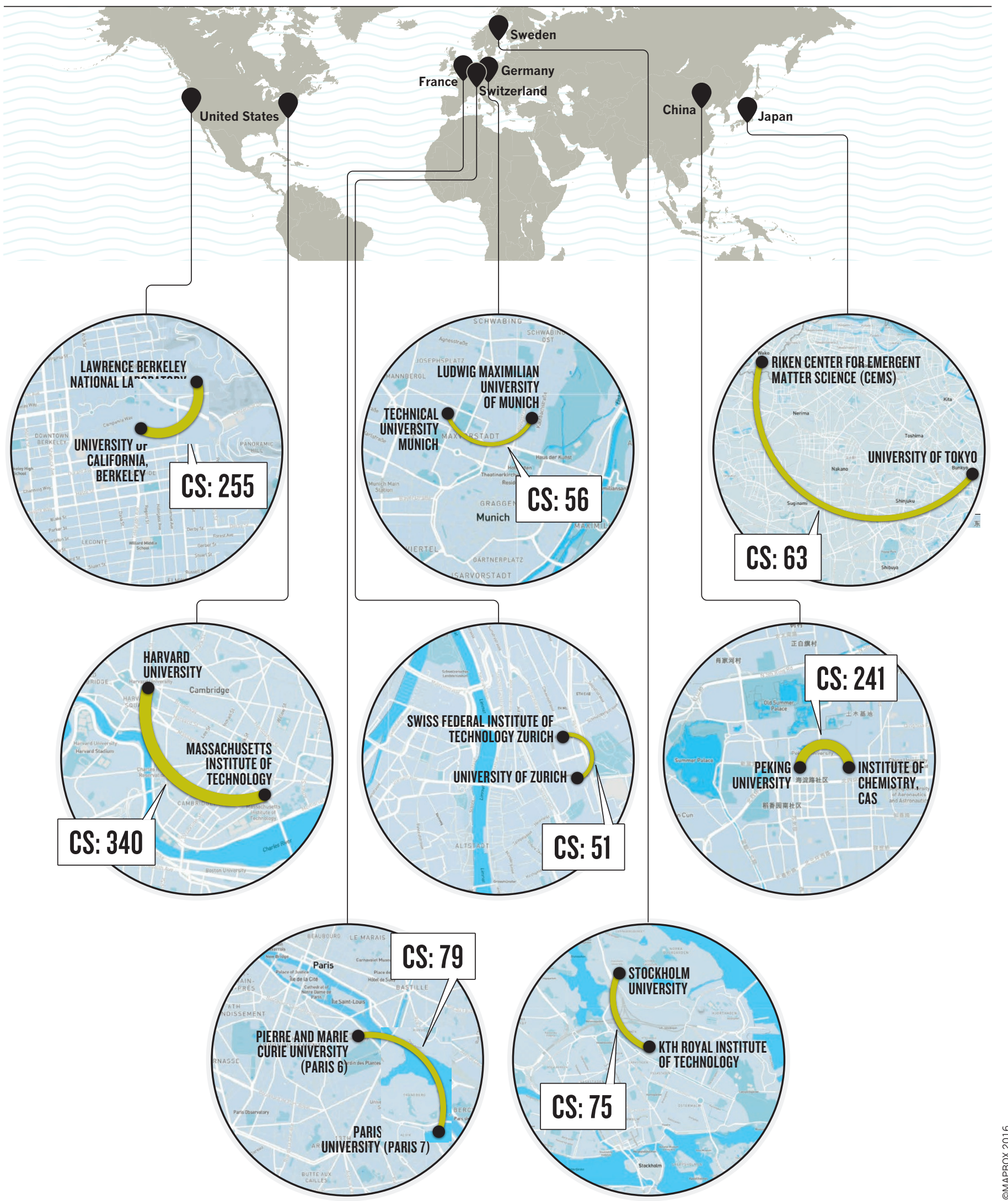


"Geographic proximity reduces transaction costs," says Maryann Feldman, a professor of public policy at the University of North Carolina at Chapel Hill, who has also used patent disclosures to identify collaborations. It's easier to arrange face-to-face meetings with someone who works nearby than with someone in another country. Even with tools such as Skype, working around time differences and dealing with occasional bad connections can add to the effort of discussion, and team members in different countries don't talk as frequently as those who can drop by each other's office or meet for lunch.

Working close by also increases the chances a researcher will hear about work that might complement their own, for instance through a process like the Broad Institute's weekly cancer meeting (see Web of connections), where researchers from the area present their work.

Being able to drop by a co-worker's labs can have practical benefits as well, says Claudia
Werker, who studies the economics of technology at Delft University of Technology in the Netherlands. That's because there are often valuable insights to glean from experiments that never make it into journals. "A reason to collaborate locally is if you need understanding of tacit knowledge," she says. She likens the process to a skilled baker demonstrating how he creates a cake. "You can have the recipe, but sometimes someone has to show you how to do it."

While sharing a neighborhood can facilitate collaborations, it isn't the determining factor in working together, the researchers say. "Geographic proximity in a certain sense hides other characteristics of the people involved in a collaboration," says Crescenzi. "We are in geographic proximity because we are in the same social networks. Even if I spend a lot of time in Harvard Square, if I am not a Harvard affiliate I have no chance of collaborating."

There are other types of proximity besides the physical, argues Werker. Social proximity makes people of similar backgrounds and jobs more likely to interact, while organizational proximity is where people work in institutions with the same kinds of procedures and goals. One reason academia and industry sometimes struggle to achieve results is because they have different timelines and expectations about publishing research results, she says. There is also cognitive or technological proximity, where people share related knowledge and a common specialized language - a microbiologist and a geneticist might find it easier to work with each other than with a software engineer.

While current proximity can instigate some collaborations, colleagues who once shared a space often continue to work together long after they've separated. "People who spend some time together as postdocs tend to collaborate," Werker says. "When they're 60 they are still working together."
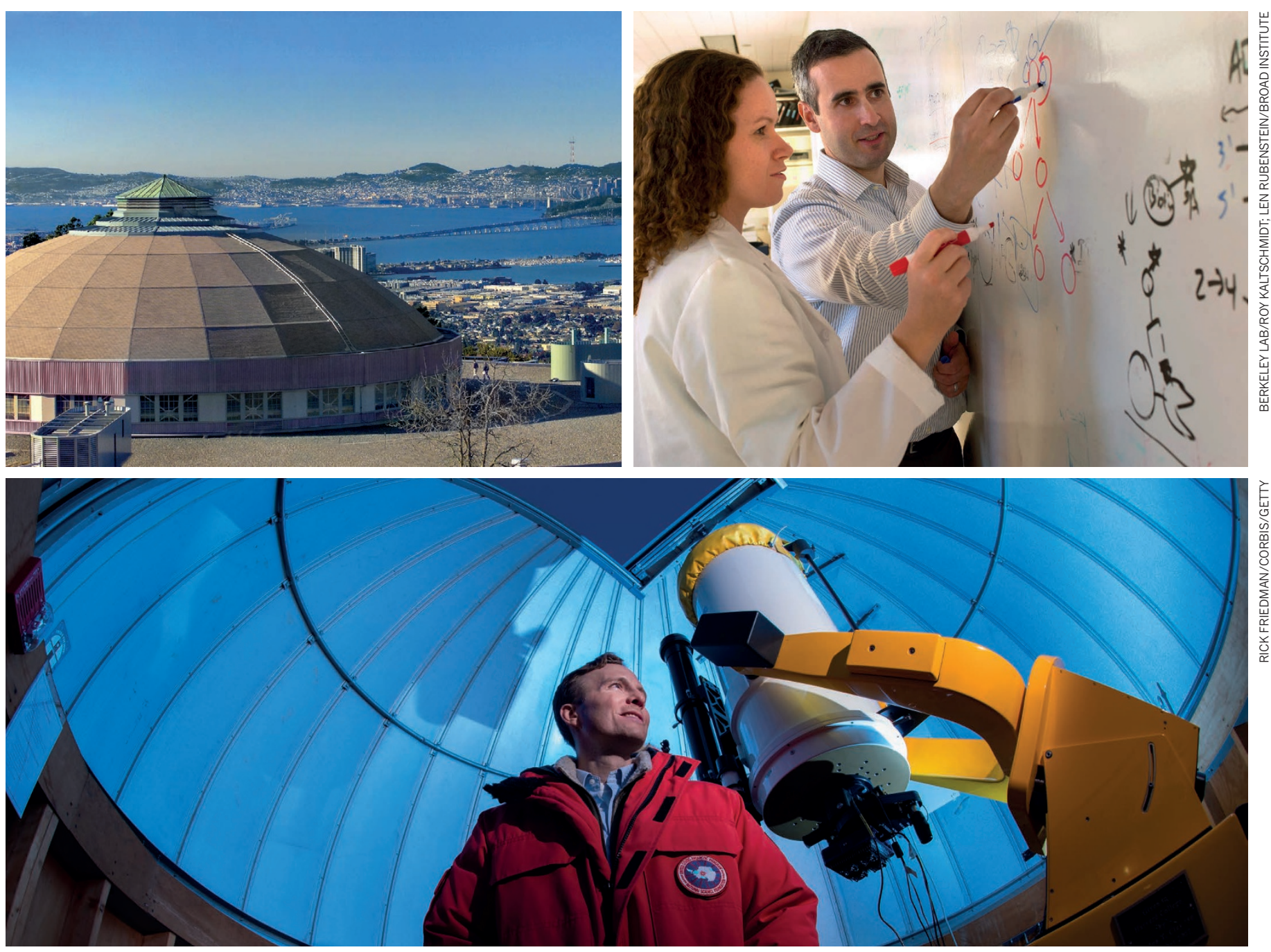

The Lawrence Berkeley Lab's synchrotron is a resource managed by the University of California, whose Bay Area branches are highly collaborative (left). Zuzana Tothova and Jesse Boehm, who work on the cancer programme at the Broad Institute, identifying genes as drug targets (right). John Kovac of the Harvard-Smithsonian Center for Astrophysics a shared venture in Cambridge, MA (bottom). 
The social, academic, and institutional networks people belong to are often the reason they're nearby in the first place, says Crescenzi. Many scientists interact because of formal relationships between separate institutions, although many of those exist only because the scientists at their respective universities had already been working together, he says.

The second-most productive collaboration in the index is between Lawrence Berkeley National Laboratory and the University of California, Berkeley. This is unsurprising. Not only are they practically next door, the university manages the laboratory, and many researchers have joint appointments.

Similarly, joint institutions drive collaborations by their very existence. The HarvardSmithsonian Center for Astrophysics in Cambridge is a shared venture between Harvard and the Smithsonian Institution, based in Washington, DC. The centre, founded in 1973 to formalize a relationship between the two institutions that began when the Smithsonian
Astrophysical Observatory moved its headquarters to Cambridge in 1955, is behind most of Harvard and the Smithsonian's shared papers published in index journals.

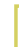

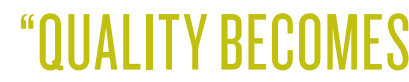 AN IMPORTANT SIGNALLING MECHANISM."}

Successful networks tend to be self-reinforcing. A university that has hired good researchers and won large grants has an easier time attracting more good researchers and grants. And being affiliated with a well-respected university suggests people have already been judged to be good at their jobs. "The quality becomes an important signalling mechanism," Crescenzi says. Feldman, though, thinks having a "name" institution isn't the determining factor. "Individual researchers care more about the people they're working with," she says.

Quality also helps explain collaborations among institutions that are not close to each other. Crescenzi says excellent research is becoming more concentrated in certain hot spots all over the world - but, thanks to the internet, those places are becoming more connected to each other.

Hong says that, despite the value of proximity, he's happy to form partnerships with researchers who live far from Cambridge. "All the people I work with are just good people and they care about doing good science, and I hope that is the driver of what would make a good collaboration," he says.

\section{A WEB OF CONNECTIONS}

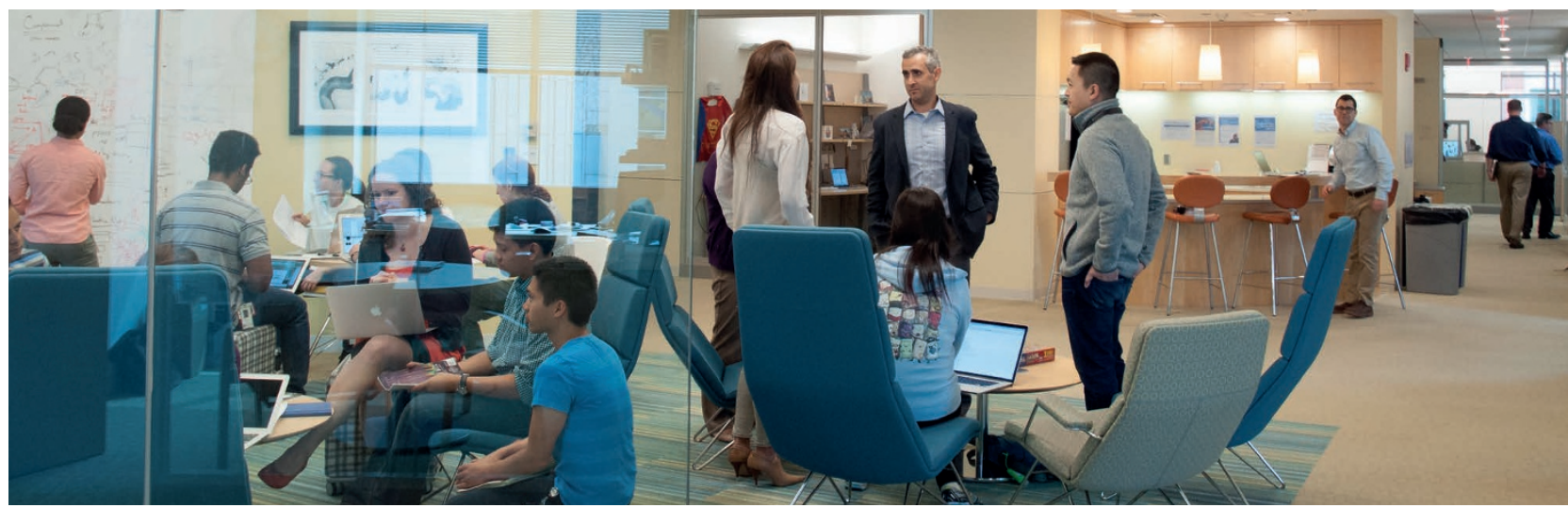

Every Tuesday, a group of cancer researchers from institutions around Boston meet at the Broad Institute of MIT and Harvard to present their work and discuss ideas.

At such a meeting in March 2014, children's cancer specialist, Andrew Hong, heard scientists from MIT's Koch Institute for Integrative Cancer Research speak about a micro-scale device they'd developed for delivering a tiny amount of a drug to a tumour.

For six months, Hong, from the Broad, had been leading a project to identify drug targets in children's cancers. He and his fellow physicians had lamented for years the paucity of treatment options for children with rare cancers.
With Broad colleagues, Yuen Yi Tseng and Jesse Boehm, the team had already collected tumour samples from cancer patients, from which they had generated cell lines. David Root, also of Broad, had then screened the cells for potential drug targets using RNA interference to turn off certain genes to see what effect that had on the tumor cells. The team had also sought the expertise of Stuart Schreiber, of Broad and the Howard Hughes Medical Institute in Maryland, who uses CRISPR to knock out genes using a different mechanism. Using the two approaches, the team had identified two genes to target with drugs. The next step was to figure out a way to test drugs on the targets in lab-grown tumours. When Hong heard the Koch Institute's Oliver Jonas, Michael Cima, and Robert Langer speak about their micro-scale device, it sounds like a perfect fit. Hong co-opted the three to their project.

They found that drugs that affected those gene targets did in fact interfere with cell growth, while a control drug did not, and that a combination of drugs worked even better. Though the drugs will need to go through a long development process before they're approved for clinical use, there is now at least a potential treatment for a cancer where there had been none. In the end, their paper in Nature Communications listed 33 co-authors affiliated with six institutions.

Collaboration is made easier by the local concentration of cancer researchers, Hong says. 